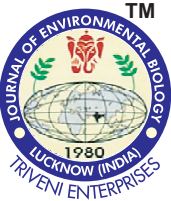

\title{
$\mathrm{JEB}$ \\ p-ISSN: 0254-8704 \\ e-ISSN: 2394-0379 \\ CODEN: JEBIDP
}

\section{Age composition of two dominant fish species in fringing shallow water of Bidong Island, South China Sea, Malaysia}

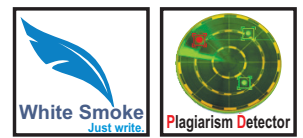

Authors Info

R. Mat Piah*, S.A. Kamaruddin, N.L. Buang and M.A. Ghaffar

School of Fisheries and Aquaculture Sciences, University Malaysia Terengganu, 21030 Kuala Terengganu, Terengganu, Malaysia.

*Corresponding Author Email : rumeaida@umt.edu.my

Key words

Bidong Island

Nemipterus furcosus

Otolith

Population dynamics

Scolopsis monogramma

Publication Info

Paper received : 06.08.2017

Revised received : 25.10 .2017

Re-revised received: 04.11 .2017

Accepted : 28.12 .2017

\section{Abstract}

Aim : The age composition of Monogrammed monocle bream, Scolopsis monogramma and Fork-tailed threadfin bream, Nemipterus furcosus in fringing shallow water of Bidong Island, South China Sea was studied for the first time.

Methodology : Fish samples were collected by baited portable traps, gill netting and hand-lining during pre-northeast monsoon season. A pair of otoliths were extracted by the open hatch method, cleaned and embedded in epoxy resin. The fish age was determined by counting the opaque zone in sectioned otoliths and was validated by marginal increment analysis.

Results : This study found that both species comprised of older fish with S. monogramma in between 4 to 9 years and 4 to 8 years in $N$. furcosus. No smaller or younger fish was observed, probably due to selective sampling efforts. The marginal increment analysis recorded an increase of $11 \%$ from August to September for $S$. monogramma and by using this increase, the growth ring was expected to be completed in April. $\ln N$. furcosus, a 14\% increase was observed and expected to be completed in January.

Interpretation : This study concluded that the S. monogramma and $N$. furcosus in the fringing shallow water of Bidong Island comprised of older individuals. Further studies should be carried out by extending the duration of sampling, using a wider range of legal mesh and hook sizes to potentially obtain a more comprehensive size range to investigate the growth parameters of the fish.

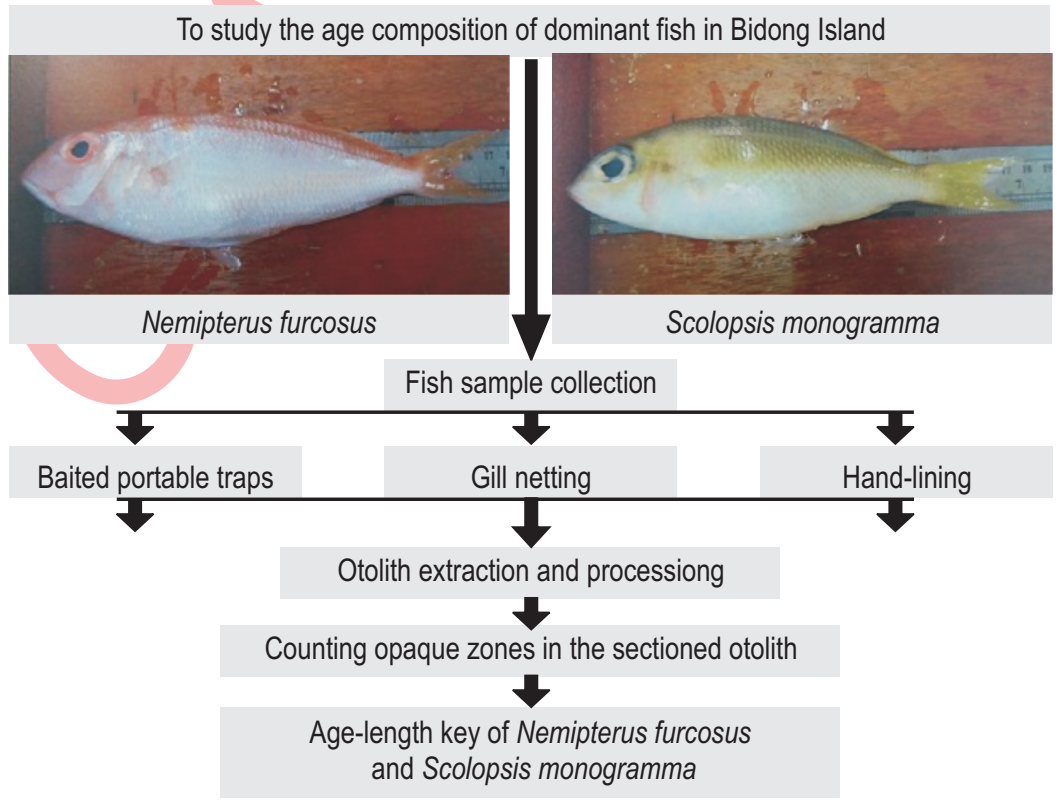




\section{Introduction}

The estimation of fish population dynamics is often based on the age structure data (Bermejo, 2007; Isey and Grubowski, 2007; Pope et al., 2010), which is important to determine the health of a population (Smith et al., 2007). For young fish, such data can provide a better understanding regarding factors that affect their recruitment success. For adults, the data can be used to determine the effects of fishing on the stocks, the efficiency of management practices, and to maximize yield for sustainable resources (Jones, 1992). Jacobsen et al. (2001) used age information to identify the abundance stability of Atlantic salmon during their feeding period in early and late winter in Norwegian Sea, while Morgan et al. (2013) used age data to assess the intraannual variations in spawning time of two gadoid species in Atlantic and North Sea.

In exploited fish stocks, fishing reduces or removes older age classes and increases the relative abundance of the younger age classes (Hidalgo et al., 2011). Cardinale and Arrhenius (2000) described the stock age structure as being a main factor affecting fish stock abundance because older fish contribute the highest number of recruits, due to more eggs produced that lead to better survival rates of larvae compared to smaller fish. Moreover, Stewart (2011) suggested that the removal of older age classes from the most heavily exploited reef-associated fish population has reduced their resilience to environmental change.

Isomaa and Kaitala (2013) recommended that data to create a fisheries management strategy should include reliable information on the age structure of the stock. The management options required to rebuild reserves of older individuals include reducing rates of exploitation, regulating maximum length to protect older fish, change gear selectivity and create "no take" protected areas (Stewart, 2011). Brunel and Piet (2013) reported that fishery management plan should consist of promoting selective fishing to protect the youngest fish to grow and have the opportunity to reproduce before being caught. Thus, the most appropriate management strategies to protect exploited fish stocks will depend on the life history of the species being studied (Stewart, 2011). This is to implement the most appropriate regulations to promote selective fishing in terms of creating gear designs and determining the maximum length of fish that can be taken for more effective management.

Bidong Island in the South China Sea is located off Terengganu waters that comprises well-developed coral reef ecosystems with various coral and rocky reef associated fishes (Matsunuma et al., 2011). However, this area is not listed as a marine park, which contribute to fishing activities in the area. Both Scolopsis monogramma and Nemipterus furcosus are the most dominant commercial species found in Bidong Island (Rumeaida et al., 2014). S. monogramma is a benthic species, usually found on sandy bottoms close to reef areas while $N$. furcosus is a demersal fish that are reportedly caught by trawls and handlines (Ambak et al., 2012). Mohsin and Ambak (1996) found that $S$. monogramma are usually caught in large quantities along with Nemipterus spp. around coral reef areas using handlines, gill nets and traps.

The dominance of $S$. monogramma and $N$. furcosus around this island not only attracts frequent gill netting activities by fishermen but also illegal trawl net operations. These activities may directly affect the population structure of these species. Knowledge on the age composition of these two species is important and can be used to assess the status of its population and will contribute to the management of the island. Therefore, this study was carried out to determine the age composition of $S$. monogramma and $\mathrm{N}$. furcosus around Bidong Island, which are the most commercially important fish species in the area, and to observe if fisheries activities are reducing their numbers of older individuals.

\section{Materials and Methods}

Fish sampling and sample analysis : This study was carried out at Bidong Island (Lat. $5.62^{\circ}$, Long $103.07^{\circ}$ ), South China Sea, Malaysia. Fish sampling was carried out at three stations located in the fringing shallow waters of the island from $15^{\text {th }}$ to $17^{\text {th }}$ August and $12^{\text {th }}$ to $14^{\text {th }}$ September, 2013 (Fig. 1). Fish samples were captured during the pre-monsoon season on a three-day sampling trip once a month, by deploying baited portable traps, gill nets and handlines. Fish were measured to nearest $0.01 \mathrm{~cm}$ in terms of total length (TL) and standard length (SL) whereas the body weight (b.w.) was measured to the nearest $0.01 \mathrm{gram}(\mathrm{g})$.

Otolith extraction, preparation and sectioning : The open hatch method was used to extract a pair of otoliths from fish following the procedures by Secor et al. (1991). Age determinations were based on the standard methods widely used in fish biology (Secor et al., 1991; Kendal et al., 2009; Pope et al., 2010). One otolith from each pair was embedded in BUEHLER epoxy resin (20-8128-032) with BUEHLER epoxy hardener at a ratio of 5:1. Otolith sectioning was performed using BUEHLER Isomet 1000 precision saw equipped with diamond watering blade $(15.2 \mathrm{~cm}$ diameter). Three thin transverse sections $(0.3 \mathrm{~mm})$ near the otolith centre were taken, which covered a wide range. The sections were dipped in $0.02 \% \mathrm{HCl}$ for $15 \mathrm{sec}$ before being mounted on a glass slide with a BUEHLER mounting wax Crystalbond (flow at $135^{\circ} \mathrm{C}$ ). The otolith section was examined under a stereomicroscope with reflected light or transmitted light to enhance the detail.

Age determination : The age of fish was estimated by counting the number of opaque zones in each otolith section as shown in Fig. 2, following the methods of Akita and Tachihara (2014) and Puentes Granada et al. (2004). To verify the age estimates, each otolith was viewed and read twice without prior knowledge of the 


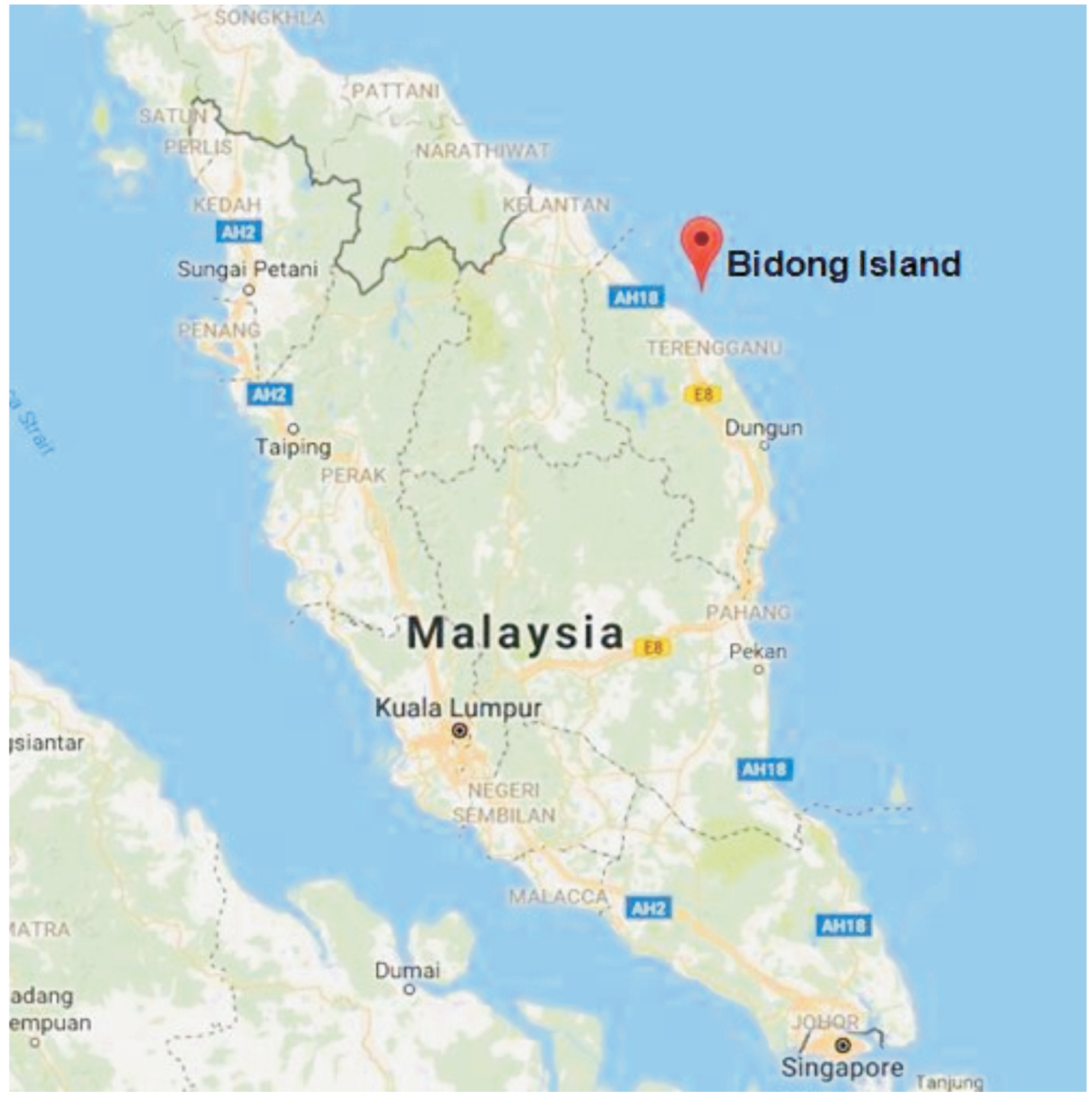

Fig. 1 : Location of sampling area of the fringing shallow water of the Bidong Island, South China Sea (Source: modification of google map)

fish length or the sampling date. If the two counts differed by more than one, the otoliths were excluded from the analysis.

Age validation : Marginal increment analysis was used to validate the fish age following the methods of Kendall et al. (2009) and Farley et al. (2013). For fish with two or more opaque growth rings, the marginal increment (MI) was defined as the distance from the most recently completed zone to the otolith edge as proportion of previous completed increment (Kendall et al., 2009).

\section{Results and Discussion}

A total of $35 \mathrm{~S}$. monogramma and $33 \mathrm{~N}$. furcosus specimens was collected and analysed. The size of $S$. monogramma range were between $12.60-22.40 \mathrm{~cm}$ standard length with an average of $16.40 \pm 0.60 \mathrm{~cm}$. Meanwhile, the size range of $N$. furcosus were just $11.00-18.00 \mathrm{~cm}$ standard length with an average of $13.20 \pm 0.40 \mathrm{~cm}$. The length frequency distribution showed that $S$. monogramma in the narrow band of 


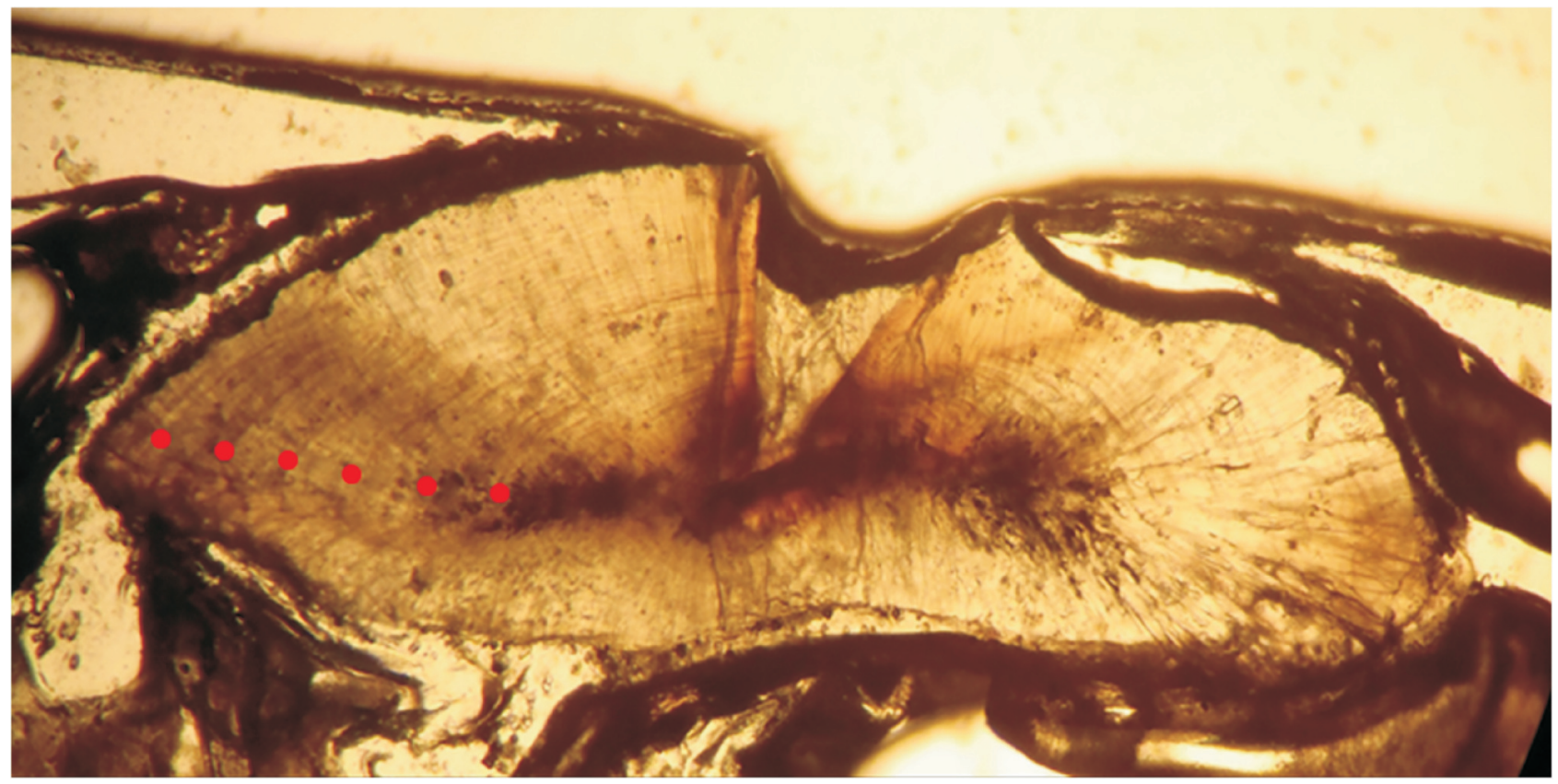

Fig. 2 : Transverse section of an otolith from a 6 year-old Nemipterus furcosus viewed under stereomicroscope, the point shows the opaque zones (dark) and between the points shows the translucent zones (light)

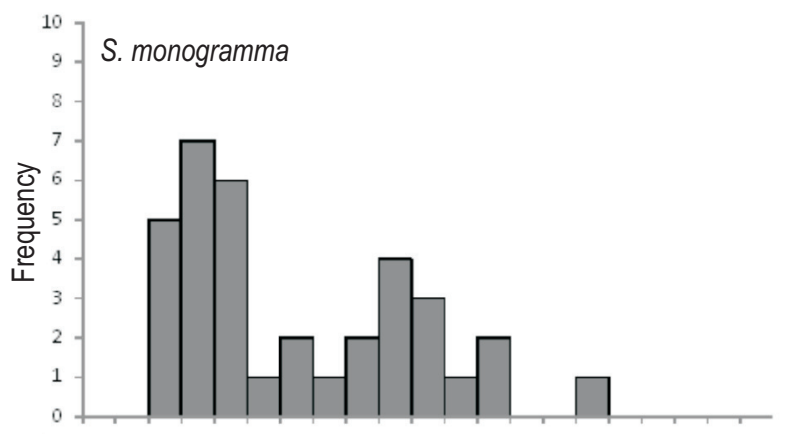

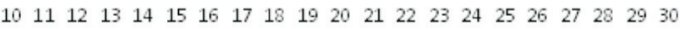
Length classes $(\mathrm{cm})$

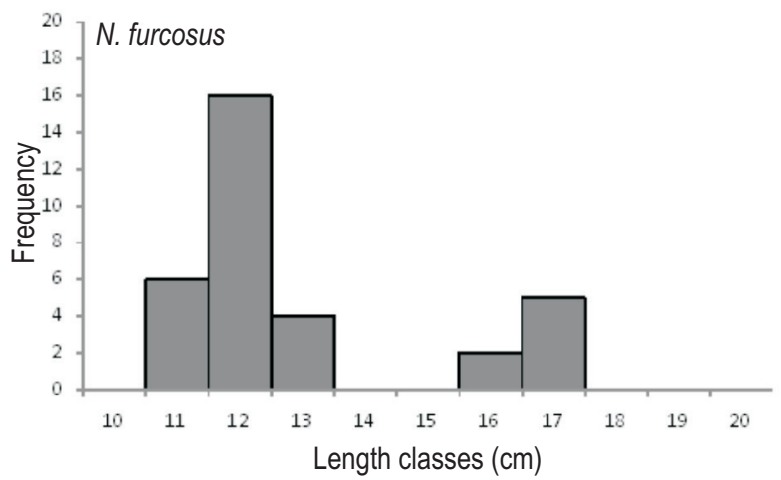

Fig. 3 : Length frequency distribution of $S$. monogramma $(n=35)$ and $N$. furcosus $(n=33)$ in Bidong Island, South China Sea
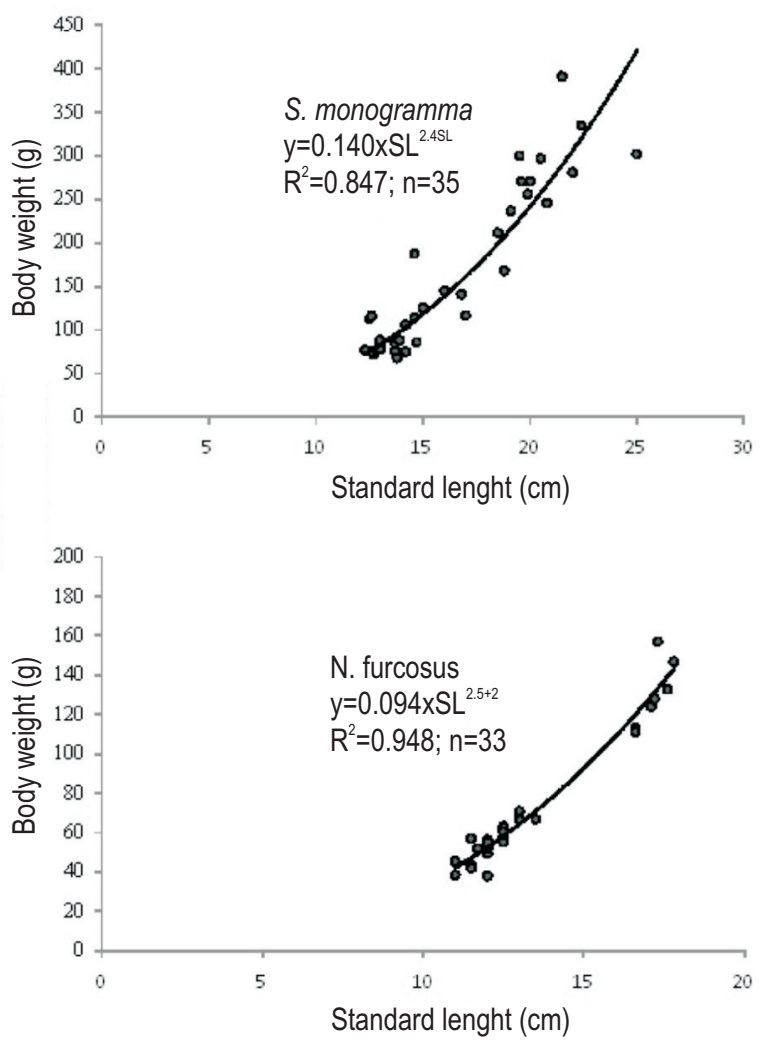

Fig. 4 : The length-weight relationship of $S$. monogramma $(n=35)$ and $N$. furcosus $(n=33)$ in Bidong Island, South China Sea 

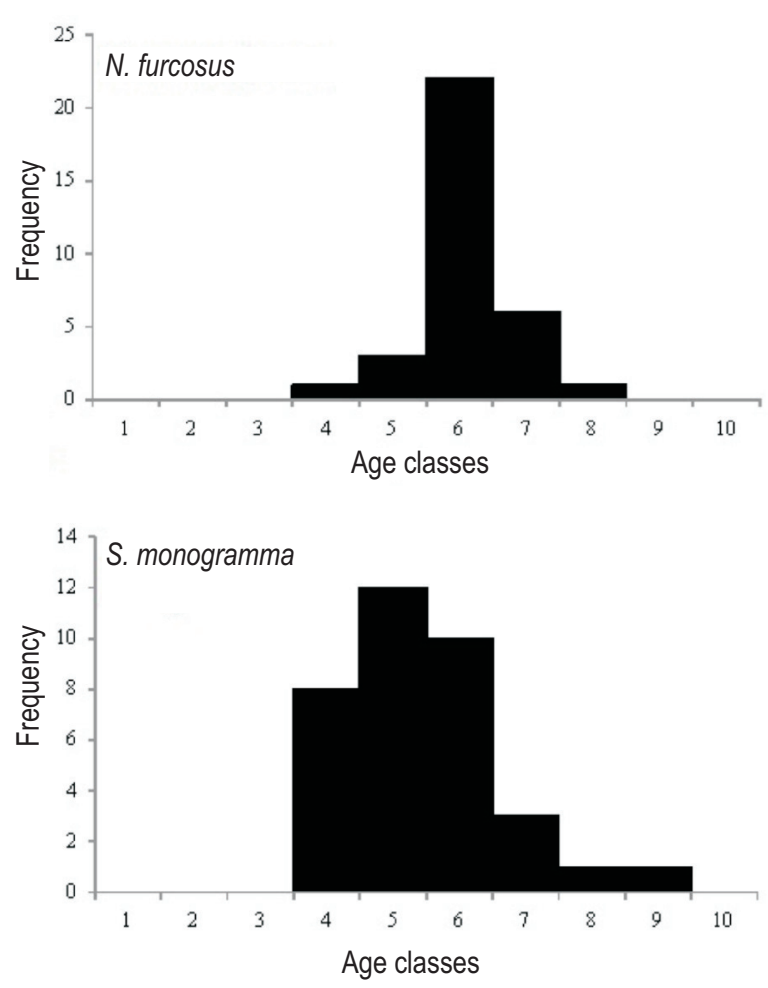

Fig. 5 : Age structure of $N$. furcosus and S. monogramma in Bidong Island, South China Sea

shallow water off Bidong Island was dominated by fish with a length size of 12.00 to $14.00 \mathrm{~cm}$ and fish with a total length of $12.00 \mathrm{~cm}$ dominated the catch of $N$. furcosus (Fig. 3).

The length weight relationships for both species showed that the $b$ values were lower compared to the value of 3 for fish of isometric growth with 2.49 for S. monogramma and 2.54 for $\mathrm{N}$. furcosus (Fig. 4).

Age composition analysis showed that $N$. furcosus in the shallow water of Bidong Island comprised of fish between 4 to 8 years of age with the dominant age of 6 years old. Meanwhile, $S$. monogramma aged between 5 to 9 year, dominated by 5 year old fish (Fig. 5). Limited age-length key of $S$. monogramma showed that the smallest fish collected in this study were $12 \mathrm{~cm}$ and up to 7 year old, while the oldest fish were 9 years old and $19 \mathrm{~cm}$ (Table 1). For $N$. furcosus the smallest and the largest collected fish collected were the youngest and the oldest fish, respectively, and average age and size were 6 years old at $16 \mathrm{~cm}$ in length (Table 2).

Limited marginal increment analysis of $S$. monogramma found that the MIA in August was 0.42 and then increased at $11 \%$ to 0.47 in September. Limited marginal increment analysis of $N$. furcosus also showed an increase of $14 \%$ from August at 0.49 to September at 0.56 , respectively.
This study found that the sample size of both species were small, even though these two species were commercially most dominant fish in this area (Rumeaida et al., 2014). Mohsin and Ambak (1996) reported that N. furcosus was abundant from July to September in Terengganu waters, which was also the sampling time in this study. Isa et al. (1998) reported that a survey in the east coast of Peninsular Malaysia in 1995 and 1996 found that both Scolopsis spp. and Nemipterus spp. commonly occur in deeper waters at 50-70 $\mathrm{m}$ in depth during pre-northeast monsoon season, which may be the reason for the small sample size for both species collected in Bidong Island.

The length frequency distribution analysis of $N$. furcosus in the shallows water of Bidong Island indicates that the size distribution was smaller than common size caught in Malaysia, that ranged between $15-25 \mathrm{~cm}$ with maximum size of $35 \mathrm{~cm}$ (Mohsin and Ambak, 1996). Mohsin and Ambak (1996) also reported that the common length of this fish in the east coast of Peninsular Malaysia was $20 \mathrm{~cm}$ compared to $12 \mathrm{~cm}$ found in this study. No study has been found on S. monogramma in Malaysia. However, a study by Akita and Tachihara (2014) in Japan recorded the bigger fish compared to fish in Bidong Island. These decreases in sizes for both species may be caused by their abundance and prey or predator species or by fishing intensity and genetic differences between local populations (Puentes Granada et al., 2004).

Length weight relationship analysis showed that both species have negative allometric growth. Isa et al. (1998) reported that the $b$ value for Nemipterus spp. in pre-monsoon season were in between 2.74 to 3.20 while Mohsin and Ambak (1996) found that the value of $b$ was in between 2.62 to 3.11 . Samad et al. (2013) however found that a study in neighboring waters also recorded negative allometric growth of $N$. furcosus for all months except in October.

This study found that the youngest fish collected for both species were 4 year old. The absence of younger fish in this study was probably due to the sampling efforts carried out by gill netting, portable traps deployment and hand-lining. Fishing gear selectivity may influence the size and age of fish collected, since fish can avoid and escape from traps, while mesh size and hook size also may select for, or against capture of certain sizes of fish (Cappo and Brown, 1996; Santos et al., 2002). However, use of effective fishing gear such as trawl net is prohibited in this island.

Akita and Tachihara (2014) reported that the maximum age for $S$. monogramma was 10 years, and the mature fish would be 3 to 5 years old. In this study, the dominant age classes found were between 4 to 6 years which may indicate that $S$. monogramma in Bidong Island are mature fish. The age composition of N. furcosus was similar to the finding of Puentes Granada et al. (2004) who reported that Nemipterus spp. did not live beyond 10 years. However, a study by Kimoto and Johari 
Table 1: Limited age-length key of Scolopsis monogramma in fringing shallow waters of Bidong Island, South China Sea

\begin{tabular}{|c|c|c|c|c|c|c|c|c|c|c|c|}
\hline \multirow{2}{*}{$\begin{array}{l}\text { Length } \\
\text { class }\end{array}$} & \multirow[b]{2}{*}{1} & \multirow[b]{2}{*}{2} & \multirow[b]{2}{*}{3} & \multicolumn{7}{|c|}{ Number of growth checks (age) } & \multirow{2}{*}{$\begin{array}{l}\text { Total } \\
\text { (n) }\end{array}$} \\
\hline & & & & 4 & 5 & 6 & 7 & 8 & 9 & 10 & \\
\hline 12 & & & & 1 & 1 & 1 & 12 & & & & 5 \\
\hline 13 & & & & 2 & 2 & 3 & & & & & 7 \\
\hline 14 & & & & 1 & 3 & 2 & & & & & 6 \\
\hline 15 & & & & & & 1 & & & & & 1 \\
\hline 16 & & & & 1 & & 1 & & & & & 2 \\
\hline 17 & & & & & 1 & & & & & & 1 \\
\hline 18 & & & & 1 & 1 & & & & & & 2 \\
\hline 19 & & & & 1 & 1 & 1 & & & 1 & & 4 \\
\hline 20 & & & & & 2 & & & 1 & & & 3 \\
\hline 21 & & & & & 1 & & & & & & 1 \\
\hline 22 & & & & 1 & & 1 & & & & & 2 \\
\hline 23 & & & & & & & & & & & 0 \\
\hline 24 & & & & & & & & & & & 0 \\
\hline 25 & & & & & & & 1 & & & & 0 \\
\hline Total & 0 & 0 & 0 & 8 & 12 & 10 & 3 & 1 & 1 & 0 & 35 \\
\hline
\end{tabular}

(n)

Table 2: Limited age-length key of Scolopsis monogramma in fringing shallow waters ofBidong Island, South China Sea

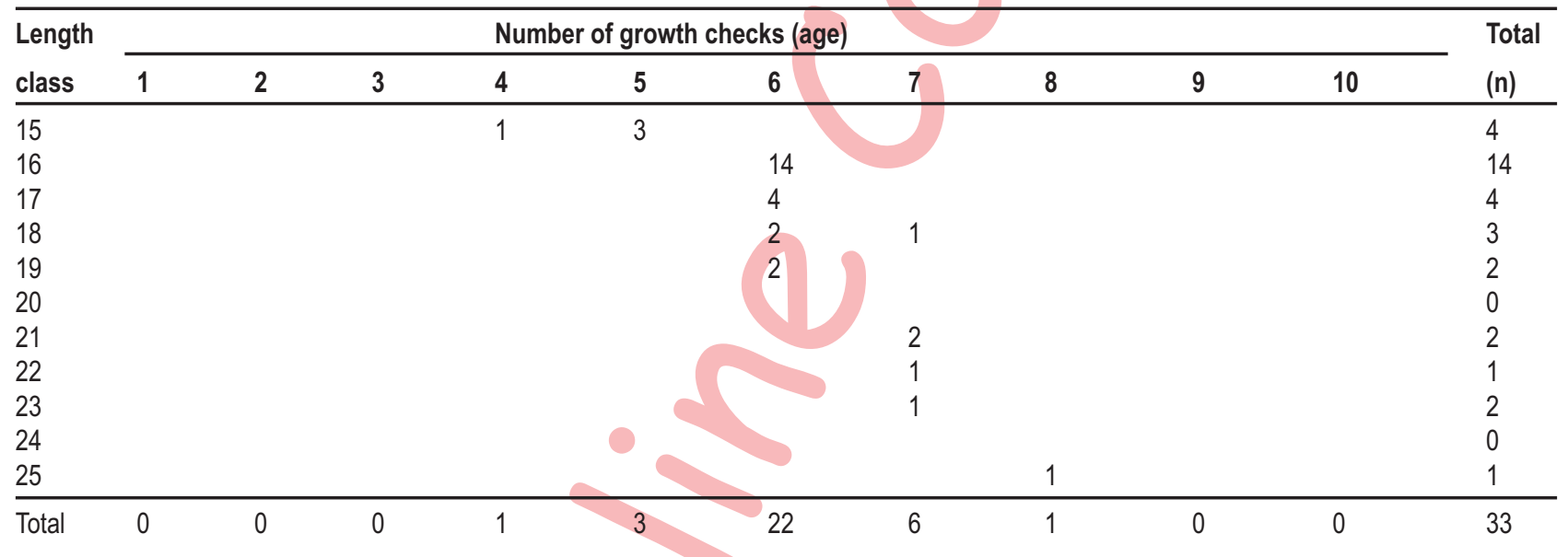

(1996) in the east coast of peninsular Malaysia reported that the maximum age of this fish was 6 years, but the age determination was carried out by length-frequency analysis which may underestimate their age. Otoliths have been reported as the most suitable structure to be used as aging tools in Nemipterid fishes (Eggleston, 1972; Puentes Granada et al., 2004), especially in older and larger fishes (Samuel, 1990).

The increase in marginal increment analysis from August to September was used to predict the timing of opaque zone formation for both species. A 11 and 14 percent increase in $S$. monogramma and $N$. furcosus showed that the growth ring or band will be completed in April for S. monogramma and in January for $N$. furcosus. The ring formation is closely associated with seawater temperature (Pajuelo et al., 2006). Distribution of sea surface temperature in South China Sea changes during monsoon (Akhir, 2012) and January was at the end of the Northeast-monsoon season in Malaysia (Mohsin and Ambak, 1996; Tan et al., 2002). Tan et al. (2002) reported that December was the coldest month, recording the lowest sea surface temperature in South China Sea and the temperature starts to increase in January. Temperature change may influence the formation of new growth ring in these two species. Pajuelo et al. (2006) also found that the opaque band of coastal sparid fish was deposited during summer when the sea water temperature increases.

In the present study, the age composition of most dominant commercially important fishes in the shallow water of Bidong Island was investigated for the first time. This preliminary 
study found that both $S$. monogramma and $N$. furcosus generally comprised of older individuals.

As selectivity of fishing gear involved in the sampling effort may influence the size, hence the age of fish collected and use of age composition data as indicator of population health in Bidong Island, further study should be carried out by improving sampling strategies through the deployment of fishing traps and gill nets with more diverse legal mesh sizes so the probability of capturing smaller and younger size fish would be higher. Further study should also be carried out by extending the duration of sampling as well as investigate the reproductive state of both species so that a better understanding on these species populations can be achieved.

\section{Acknowledgments}

The authors would like to thank everyone involved in this study, especially the staff of Fisheries Science Laboratory. The authors would like to thank Universiti Malaysia Terengganu for the logistic and financial support, and School of Fisheries and Aquaculture Sciences for providing the laboratory facilities. This study was carried out under the Universiti Malaysia Terengganu research grant (GGP:68007/2013/95).

\section{References}

Akhir, M.M.F.: Surface circulation and temperature-distribution of Southern South China Sea from Global Ocean Model (OCCAM). Sains Malays., 41, 701-714 (2012).

Akita, Y. and K. Tachihara: Age, growth, maturity and sex changes of monogrammed monocle bream Scolopsis monogramma in the waters around Okinawa-jima Island, Japan. Fish. Sci., 80, 679-685 (2014).

Ambak, M.A., M.M. Isa, M.Z. Zakaria and M.A. Ghaffar: Fishes of Malaysia. pp. 159-166. Second Edition, Penerbit Universiti Malaysia Terengganu, (2012).

Bermejo, S.: Fish age classificaltion based on length, weight, sex and otolith morphological features. Fish. Res., 84, 270-274 (2007).

Brunel, T. and G. J. Piet : Is age structure a relevant criterion for the heath of fish stocks. ICES J. Mar. Sci., 70, 270-283(2013).

Cardinale, M. and F. Arrhenius: The relationship between stock and recruitment: Are the assumptions valid? Mar. Ecol. Prog. Ser., 196, 305-309 (2000).

Cappo, M. and I.W. Brown: Evaluation of sampling methods for reef fish populations of commercial and recreational interest. $72 \mathrm{p}$. Technical report No. 6. CRC Reef Research Centre Ltd., Townsville, Australia (1996).

Eggleston, D.: Patterns of biology in the Nemipteridae. J. Mar. Biol. Ass. India, 14, 357-364 (1972).

Farley, J.H., A.J. Williams, N.P. Clear, C.R. Davies and S.J. Nicol: Age estimation and validation for South Pacific Albacore Thunnus alalunga. J. Fish. Biol., 82, 1523-1544 (2013).

Hidalgo, M., T. Rouyer, J.C. Molinero, E. Massuti, J. Moranta, B. Guijarrp and N.C. Stenset: Synergistic effects of fishing-induced demographic changes and climate variation on fish population dynamics. Mar. Ecol. Prog. Ser., 426, 1-12 (2011).
Isa, M.M., A.H.H.A. Arshad and S. Basir: Distribution, abundance and biological studies of economically important fishes in the South China Sea, Area I: East Coast of Peninsular Malaysia. S4/FB1<MANSOR>SEAFDEC. Marine Fishery Resources Development and Management Department of Southeast Asian Fisheries Development Center, Kuala Terengganu, Malaysia (1998).

Isey, J.J. and T.B. Grabowski: Age and growth. Analysis and interpretation of freshwater fisheries data (Eds.: C.S. Guy and M.L. Brown). American Fisheries Society, Bethesda, Maryland, pp.187228 (2007).

Isomaa, M., V. Kaitala and J. Laakso: Determining the impact of initial age structure on the recovery of a healthy over-harvested population. Ecol. Modell., 286, 45-52 (2013).

Jacobsen, J. A., R.A. Lund, L. P. Hansen and N. O'Maoileidign: Seasonal differences in the origin of Atlantic salmon (Salmo salar L.) in the Norwegian Sea based on estimates from age structures and tag recapture. Fish. Res., 52, 169-177 (2001).

Jones, C. M.: Development and application of the otolith technique. Otolith microstructure examination and analysis (D.K. Stevenson and S.E. Campana). Can. Spec. Publ. Fish. Aquat. Sci., 117 (1992).

Kendall, B.W., C. A. Gray and D. Bucher: Age validation and variation in growth, mortality and population structure of Liza argentea and Myxus elongatus (Mugilidae) in two temperate Australian esturaies. J. Fish. Biol., 75, 2788-2804 (2009).

Kimoto, $\mathrm{H}$. and I. Johari: The stock status and management scheme of kerisi on the east coast of peninsular Malaysia. SEAFDEC MFRDMD/RES/1. Marine Fishery Resources Development and Management Department of Southeast Asian Fisheries Development Center, Kuala Terengganu, Malaysia (1996).

Matsunuma, M., H. Motomura, K. Matsuura, N. A. M. Shazili and M. A. Ambak: Fishes of Terengganu-East Coast of Malay Peninsula, Malaysia. National Museum of Nature and Science, Tokyo, Universiti Malaysia Terengganu, Terengganu and Kagoshima University Museum, Kagoshima, pp. 251 (2011).

Mohsin, A. B. K. and M. A. Ambak: Marine fishes and fisheries of Malaysia and neighbouring countries. University Pertanian Malaysia Press, pp. 320-327 (1996).

Morgan, J. M., P. J. Wright and R. M. Rideout: Effect of age and temperature on spawning time in two gadoid species. Fish. Res., $138,42-51$ (2013).

Pajuelo J. G., I. Martinez, J. A. Gonzalez, J. M. Lorenzo, A. GarciaMederos, R. Dominquez-Seoane and C. M. Hernamdez-Cruz : Growth pattern and age estimation of the coastal sparid fish Pagrus auriga on the Canary Islands shelf. Fish. Res., 82, 7-13 (2006).

Pope, K. L., S. E. Lochmann and M. K. Young : Methods for assessing Fish Populations. Nebraska Cooperativ, Fish \& Wildlife Research Unit -- Staff Publications. Paper 73. in M. C.; QuistM.C.;Hubert, W.A.; [eds] Inland fisheries management in North America. 3rd Edn., American Fisheries Society, Bethesda, Maryland (2010).

Puentes Granada, V., Y. Masuda and T. Matsuoka:Age and growth of the yellowbelly threadfin bream Nemipterus bathybius in Kagoshima Bay, Southern Japan. Fish. Sci., 70, 497-506 (2004).

Rumeaida, M. P., S. M. M. Daud and F. M. I. Badri: Fish diversity and abundance in Bidong Island, South China Sea, Malaysia. AACL. Bioflux, 7, 176-183 (2014).

Samad, A. F., M. M. Rahman and S. Saad: Growth, condition factor, 
maturity, gonadal development and spawning of fork-tail threadfin bream (Nemipterus furcosus) in the Coastal water of Pahang. International Conference on Oceanography and Sustainable marine production: A challenge of managing marine resources in a changing climate, 28-30 October 2013, Malaysia (2013)

Samuel, M.: Biology, age, growth and population dynamics of thread fin bream Nemipterus japonicas. J. Mar. Biol. Assoc. India, 32, 66-76 (1990).

Santos, M. N., M. B. Gaspar, P. Vasconcelos and C. C. Monteiro: Weightlength relationships for 50 selected fish species of the Algarve Coast (Southern Portugal). Fish. Res., 59, 289-295 (2002).

Secor, D. H., J. M. Dean and E. H. Laban: Manual for otolith removal and preparation for microstructural examination. Technical Publication 1991-01. Belle W. Maruch Inst., 41-43 (1991).

Smith, M. A., M. A. Pegg and K. S. Irons: Analysis of fish age structure and growth in the Illinois River. U.S. Geological Survey, Upper Midwest Environmental Sciences Center, LaCrosse, Wisconsin, June 2007. LTRMP Technical Report2007-T002, p. 55 (2007).

Stewart, J.: Evidence of age-class truncation in some exploited marine fish populations in New South Wales, Australia. Fish. Res., 108, 209-213 (2011).

Tan, A. K., S. Mansor, H. M. Ibrahim and A. Rashid: Studies of sea surface temperature and chlorophyll-a variations in East Coast of Peninsular Malaysia. Pertanika J. Sci. Technol., 10, 13-24 (2002).
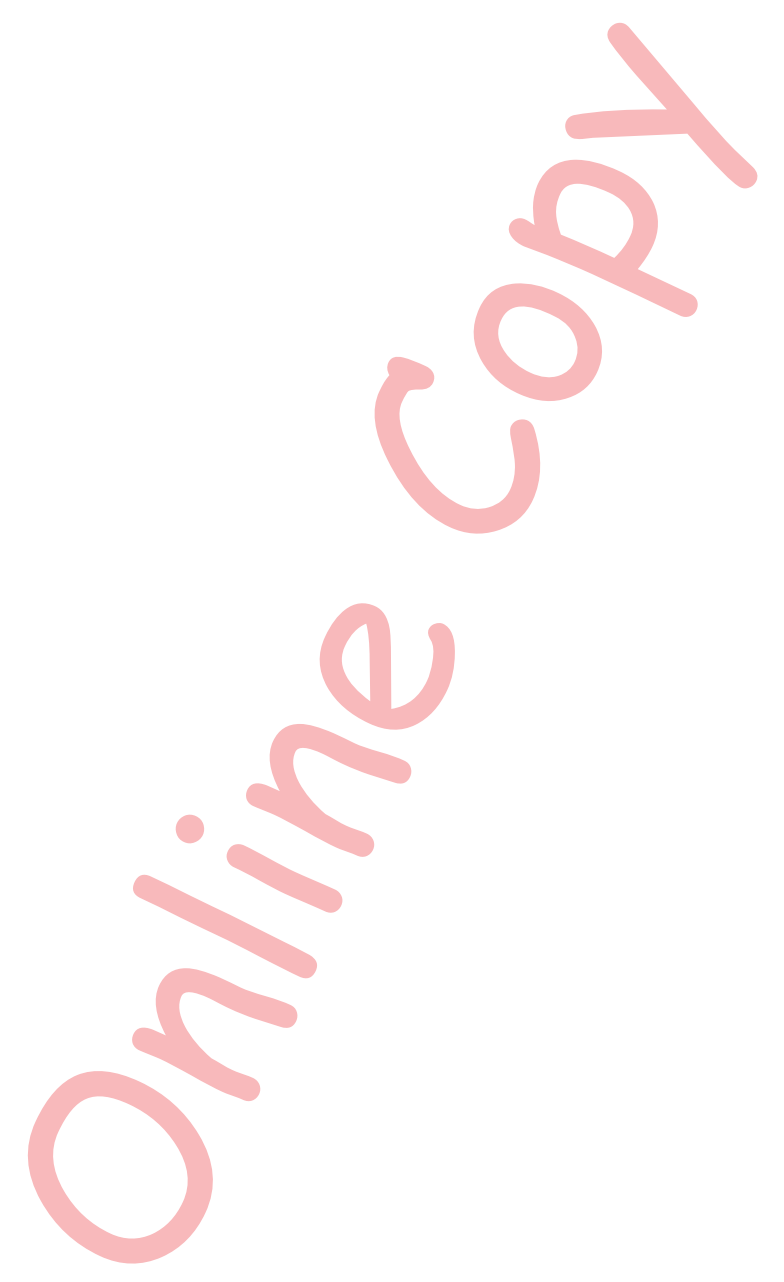